\title{
APRENDIZAGEM COM MOBILIDADE NA PERSPECTIVA DIALÓGICA: REFLEXÕES E POSSIBILIDADES PARA PRÁTICAS PEDAGÓGICAS*
}

\author{
Ms. Paulo Gaspar Graziola Junior** - UNISINOS - pgraziola@gmail.com
}

RESUMO. No contexto da aprendizagem com mobilidade (m-learning) apoiada pelo uso de Tecnologias Móveis Sem Fio (TMSF), surge o problema que deu origem a pesquisa, "Como as TMSF podem contribuir para práticas pedagógicas numa perspectiva dialógica, colaborativa e cooperativa?". A metodologia utilizada foi estudo de caso, a partir da análise de duas situações de práticas pedagógicas, por meio da observação direta e pesquisa participante. Os resultados são válidos para provocar a reflexão de professores/orientadores sobre a necessidade de desenvolver práticas pedagógicas capazes de dar conta das especificidades relacionadas ao processo de ensino e de aprendizagem nessa modalidade, superando o paradigma educacional vigente e estando mais perto do contexto de aprendizagem dos sujeitos.

Palavras-chave: aprendizagem com mobilidade. tecnologias móveis sem fio. práticas pedagógicas. ensino. aprendizagem.

ABSTRACT. In the context of the mobile learning (m-learning), supported by the use of wireless mobile technologies (WMTs) come the problem that was the starting point to this research, in which I was willing to "investigate how the WMTs can contribute to the teaching practices in a dialogical, collaborative and cooperative perspective". The methodology that was used to the development of the research was the study case, using direct observation and participative research. The results are valid to provoke the reflection of the teacher's role on the necessity to develop practical pedagogical able to well give the specificities related to the process of education and learning in this modality, overcoming the effective educational paradigm and being closer to the learning context of the citizens.

Key words: mobile learning. wireless mobile technologies. teaching practices. teaching. learning.

\footnotetext{
* Este trabalho faz parte da dissertação de mestrado defendida pelo Programa de Pós-Graduação em Educação da Unisinos (GRAZIOLA JUNIOR, 2009). Contou com o apoio financeiro (bolsista) do Conselho Nacional de Pesquisa (CNPq).

** Mestre em Educação pela Universidade do Vale do Rio dos Sinos - UNISINOS; Graduação em Ciência da Computação - UNISC; Participante do Grupo de Pesquisa Educação Digital - GPe-du UNISINOS.

V. $7 \mathrm{~N}^{\mathrm{o}}$ 3, dezembro, 2009
} 


\section{Introdução}

As mudanças no contexto social e educacional, provocadas pelo constante avanço tecnológico e científico, e as exigências de um mercado de trabalho altamente competitivo, por pessoas cada vez mais qualificadas, empreendedoras, inovadoras, capazes de aprender a resolver problemas cooperativamente são crescentes. No entanto, no âmbito das Instituições de Ensino, há uma dificuldade em desenvolver e vivenciar práticas pedagógicas efetivamente inovadoras, de forma a contribuir na formação desse "perfil" de profissional. Diferentes Tecnologias Digitais (TDs) têm surgido e contribuido no sentido de propiciar o desenvolvimento de práticas que possam ampliar os espaços para além da sala de aula formal, minimizando as barreiras impostas pelo tempo e pelo espaço, ajudando na ampliação dos processos de ensino e aprendizagem e na criação de comunidades de aprendizagem. Mas como criar condições para que isto possa ocorrer? Que TDs efetivamente podem ajudar a melhor aproveitar o tempo que temos? Como propiciar práticas pedagógicas para além do contexto formal físico e presencial? As Tecnologias da Informação Móveis e Sem Fio (TMSF), aliadas a metodologias adequadas à natureza desse meio, podem representar uma possibilidade de resposta a essas indagações?

As potencialidades da TMSF precisam ser compreendidas e avaliadas para ampliar e melhorar as práticas pedagógicas e, conseqüentemente, os processos de ensino e de aprendizagem.

Por meio da análise das interações dos sujeitos que participaram do estudo, procuramos compreender como eles se relacionam e quais as especificidades dos processos elaborados. Também, as formas pelas quais os sujeitos atingiram os resultados encontrados, e a maneira pela qual se manifestaram os diferentes tipos de interações entre os interlocutores do processo de aprendizagem via m-learning.

Novos meios tecnológicos, nesse caso, as TMSF, por si só não se constituem em inovações nos processos de ensino e de aprendizagem, na medida em que a inovação implica na superação de paradigmas. Essa compreensão tem povoado a mente de professores/pesquisadores que se apropriam das tecnologias, utilizando-as de forma crítica, refletindo sobre o que representam no contexto do desenvolvimento humano, das organizações e das sociedades, deslocando a compreensão equivocada de que a tecnologia é a inovação, para compreendê-la como propulsora do surgimento de inovações, as quais surgem no conhecer, portanto no viver e conviver.

A partir da Revisão de Literatura, no qual realizo um movimento de mapeamento da produção do conhecimento acerca das práticas pedagógicas com a utilização de TMSF sob a perspectiva da aprendizagem com mobilidade, entendo que o presente estudo avança na produção do conhecimento na área, na medida em que foca especificamente na questão que é apresentada como sendo uma das mais frágeis no contexto da aprendizagem com mobilidade, se considerarmos os projetos existentes, que é a questão didático-pedagógica. O presente estudo se propõe não somente analisar uma prática pedagógica com o uso de TMSF, buscando subsídios para compreender como se configura uma prática com o uso dessas tecnologias, mas, principalmente, se propõe, a partir desses subsídios, construir uma prática numa perspectiva dialógica, colaborativa e cooperativa, analisando esse processo.

Assim, o objetivo geral desse estudo consistiu em compreender "como as TMSF podem contribuir para práticas pedagógicas numa perspectiva dialógica, colaborativa e cooperativa”. Os objetivos específicos são os seguintes:

- Compreender como se configura uma prática pedagógica com o uso das TMSF; 
- Compreender como a questão do tempo, do espaço, enfim, da mobilidade, influencia no desenvolvimento de práticas pedagógicas com o uso de TMSF;

- Compreender como se manifesta a interação, o diálogo, a colaboração e a cooperação no contexto das práticas-pedagógicas com o uso de TMSF;

- Compreender como os envolvidos no processo formativo "hospedam" essa tecnologia;

- Compreender as implicações do uso da mobilidade no processo de ensino e de aprendizagem.

Esses objetivos foram perseguidos tendo como base a fundamentação teórica apresentada a seguir.

\section{Fundamentação Teórica}

Segundo Castells (2005), uma revolução tecnológica centrada nas tecnologias da informação e da comunicação está remodelando a base material da sociedade em ritmo acelerado. Há um movimento intenso e crescente de redes interativas de computadores, criando novas formas e canais de comunicação, moldando a vida e simultaneamente, sendo moldadas por ela. Assim, a rápida evolução das tecnologias e das telecomunicações provoca mudanças em todos os setores da sociedade, contribuindo para o surgimento da chamada "Sociedade em Rede". Lemos (2002, p. 147) afirma que "hoje, rede significa uma estrutura telemática ligada a conceitos como interatividade, simultaneidade, circulação e tactilidade".

O planeta está imerso numa cultura global que nasce com o advento dos meios de comunicação unidos às TDs. A essa cultura, chama-se Cibercultura. Para Lemos (2002), a cibercultura é a associação da cultura contemporânea às TDs, aliando a técnica à vida social. São os nossos novos modos de vida permeados pela comunicação instantânea, pela rapidez da informação, pela possibilidade de intervenção e criação de novas informações que caracterizam primordialmente a cibercultura. Assim, a cibercultura indica um novo modelo de viver e de se relacionar com o outro. O respeito ao outro se faz imprescindível na cultura de rede, na comunicação, porque ninguém se comunica sozinho e a rede só existe na intersecção de diversos "nós". Essas modificações nas formas sociais, nas práticas dessa cibercultura, trazem à tona também mudanças em relação a reconfigurações de tempo e espaço.

Partindo da idéia de que o espaço e tempo estão interligados na natureza e na sociedade, Castells (2005) faz uma análise sobre o significado social do espaço e do tempo: "o espaço organiza o tempo na sociedade em rede" (p. 403).

$\mathrm{Na}$ sociedade em rede é o espaço, não mais físico, mas o de fluxos de informação, que passa a organizar o tempo. Castells opõe o novo espaço de fluxos ao espaço de lugares que historicamente enraizou a experiência social. Para o autor, o espaço de fluxos é "a organização material de práticas sociais de tempo compartilhado, que funcionam por meio de fluxos. Por fluxos entendem-se as sequências intencionais, repetitivas, e programáveis de intercâmbio e interação entre posições fisicamente desarticuladas, mantidas por atores sociais nas estruturas econômica, política e simbólica da sociedade". (Castells, 2005, p. 436). Esse novo espaço de fluxos, presente na sociedade em rede, marca a presença da fragmentação do tempo, anteriormente considerado linear, irreversível, mensurável e previsível, o qual é definido por Castells (2005) como "tempo intemporal". O tempo intemporal pertence ao espaço de fluxos, ao passo que a disciplina tempo, o tempo biológico, cronológico, e a sequência socialmente determinada, caracterizam os lugares em todo o mundo, estruturando e desestruturando materialmente nossas sociedades segmentadas. 
Nesse sentido, com o advento das TDs, os efeitos sobre a dimensão espacial da vida cotidiana das pessoas são inúmeros. Cada vez mais as pessoas trabalham, administram serviços e estudam a partir de suas casas. Em função da necessidade de mobilidade das pessoas distantes tanto temporalmente quanto geograficamente, aliada à flexibilidade propiciada pelas emergentes TMSF, podem ocorrer processos de aceitação (hospedagem) dessas tecnologias pelos sujeitos. Na Teoria da Metáfora da Hospitalidade, proposta por Ciborra (2002), a tecnologia é tratada como um hóspede. Esse hóspede pode ser entendido como um convidado com o qual se aceita conviver ou como alguém que pode nos ser hostil. Nesse contexto, hospitalidade refere-se a tratar essa tecnologia com um olhar estranho e ambíguo, pois ao permitirmos e aceitarmos esse "hóspede" podemos considerá-lo amigo ou inimigo.

Assim, ao adotarmos uma tecnologia e a hospedarmos no nosso dia-a-dia é preciso, muitas vezes, redefinirmos a forma como nos organizamos e desenvolvemos processos de trabalho, rotinas, atividades, enfim, resignificando-as nesse novo contexto, o que também é imprescindivel quando nos referimos a processos educativos, principalmente no âmbito da própria prática pedagógica. Ao redefinirmos, estamos reinterpretando nossas próprias identidades. Ciborra (2002) coloca que as pessoas vão interagir e procurar adaptar a tecnologia, tornando familiar o que é estranho.

Desta forma, ao compreender a prática pedagógica como articulada a uma educação como prática social e ao conhecimento como produção histórica e cultural, datado e situado, entendemos que a Educação na atualidade precisa, necessariamente, contemplar em suas práticas pedagógicas o uso de diferentes TDs, enquanto uma produção histórica e cultural, que faz parte do viver e do conviver cotidiano dos sujeitos na sociedade atual.

Novos modelos educacionais estão se desenvolvendo na tentativa de possibilitar novas formas de comunicação e de interação, que permitam aos sujeitos participarem de um processo de crescimento, de diferenciação, de retomada recíproca de singularidades e de construção de cidadania. Portanto, além de estudar as novas possibilidades oferecidas pelas TDs, devemos ter presente a profunda necessidade de entender como ocorre a aprendizagem para poder ser coerente com o modelo epistemológico adotado.

Assim, as práticas pedagógicas foram fundamentadas numa concepção interacionista, priorizando a interação, a ação do sujeito com o objeto de conhecimento, entendendo como objeto de conhecimento tudo o que envolve o sujeito em seu meio físico e social. É a partir dessa interação, que o sujeito constrói o conhecimento. $\mathrm{Na}$ perspectiva da educação digital, numa concepção interacionista, o aluno deixa de ser o receptor de informações para tornar-se o co-responsável pela construção de seu conhecimento, usando o computador e diferentes TDs para buscar, selecionar, interrelacionar informações significativas na exploração, reflexão, representação e depuração de suas próprias ideias, segundo seu estilo de pensamento. Professores e alunos desenvolvem ações em parceria, por meio da colaboração, da cooperação e da interação com o contexto, com o meio ambiente e com a cultura circundante.

Conforme Schlemmer (2005, p. 106) com relação ao uso de TDs no processo educacional

quando falamos em concepção interacionista, falamos em ambientes virtuais de aprendizagem, comunidades virtuais de aprendizagem, espaços nos quais os sujeitos podem interagir e construir conhecimento. Nesse sentido o computador é visto como uma tecnologia para o desenvolvimento cognitivo.

Essas TDs priorizam a interação e o diálogo como elementos fundamentais para a construção colaborativa e cooperativa do conhecimento, propiciando a aprendizagem. 
Para isso a prática pedagógica foi fundamentada numa perspectiva dialógica, conforme o conceito de Fernandes (2006, p. 376)

prática caracterizada pela aprendizagem do professor com seus alunos. Estes, por meio do diálogo, aprendem também que o compromisso da parceria é fundamental em uma relação humana horizontal, que não exclui do professor a responsabilidade de direção do processo de ensinar e aprender, nem exime o aluno da responsabilidade de ultrapassar os limites de sua prática, recriando o espaço-tempo da reflexão e da cultura em relações democráticas e éticas.

Assim, as TMSF na relação social de interação/diálogo/cooperação como dispositivos emergentes da nova cultura da mobilidade podem contribuir para essa otimização do tempo assíncrono e fluído, esse espaço de fluxos, esse tempo intemporal, promovendo uma maior circulação da informação, favorecendo o desenvolvimento da autonomia, propiciando diversos contextos tanto formais quanto não formais de ensino e de aprendizagem.

As novas formas de aprendizagem, introduzidas pelas TDs, como no caso da aprendizagem com mobilidade, podem gerar uma maior interação entre os participantes. Assim, é preciso refletir acerca das modificações que são introduzidas na relação sujeito-computador e sujeito-sujeito da interação. No rumo desta reflexão, cabe perguntar: como propiciar espaços que promovam a interação e o diálogo de forma que resultem em processos de colaboração e cooperação?

\section{Aprendizagem com mobilidade (m-learning)}

A crescente necessidade de mobilidade de pessoas, de acesso e troca de informações em qualquer tempo e espaço, de compartilhamento de idéias, de experiências e de conhecimento, além da necessidade de ampliar os espaços formais de educação, oportunizam o emprego da emergente aprendizagem com mobilidade ( $\mathrm{m}$ learning).

A aprendizagem com mobilidade (m-learning) é possibilitada por meio do desenvolvimento e aplicação de TMSF, que são dispositivos computacionais portáteis, tais como PDAs (Assistentes Pessoais Digitais), palmtops, laptops, smartphones, dentre outros, que utilizam redes sem fio. O uso de TMSF, aliado à interação com atores humanos distantes geograficamente e fisicamente, pode propiciar que ocorram processos de ensino e de aprendizagem.

Sob o ponto de vista tecnológico, conforme Meirelles et al. (2004, p. 4):

[...] duas categorias de sistemas finais começam a ganhar popularidade mundial. A mais antiga é representada pelos $P D A$ s, com uma estimativa no Brasil de aproximadamente dois milhões de usuários. A segunda categoria é representada pelos chamados telefones inteligentes (smartphones), que além das funcionalidades dos bons $P D A$ s, permitem a comunicação por voz, navegação na internet, disponibilizando em alguns modelos conexões Bluetooth e Wi-Fi.

Sistemas gerenciadores de aprendizagem com código aberto poderão ter suas funcionalidades ampliadas, suportando novas aplicações destinadas a migrar ferramentas de comunicação para PDAs (Correio Eletrônico, Fórum, Diário de Bordo), acrescidas de rotinas para sincronização de dados com o servidor. Desta forma, tanto o trabalho off-line como o trabalho on-line poderá ser efetuado sem restrição de tempo e de espaço geográfico.

Para Reinhard et al. (2007, p. 1),

aprender com mobilidade não é uma idéia nova - a possibilidade de aprender em qualquer lugar e a qualquer momento sempre foi buscada e potencializada com ferramentas como livros, cadernos e outros instrumentos móveis

V. $7 \mathrm{~N}^{\mathrm{o}}$ 3, dezembro, 2009 
(portáteis) que existem há muito tempo. O que hoje ocorre é que as TMSF podem contribuir para a Aprendizagem com Mobilidade por disponibilizarem aos sujeitos o acesso rápido a uma grande e diversificada quantidade de informações, viabilizando seu recebimento e envio (quando associadas à Internet); além disso, essas tecnologias promovem a comunicação e a interação entre pessoas distantes geograficamente e temporalmente, de uma maneira sem precedentes.

Marçal et al. (2005, p. 3) colocam que,

[...] o m-learning surge como uma importante alternativa de ensino e treinamento à distância, na qual podem ser destacados os seguintes objetivos: - melhorar os recursos para o aprendizado do aluno, que poderá contar com um dispositivo computacional para execução de tarefas, anotação de idéias, consulta de informações via internet, registro de fatos através de câmera digital, gravação de sons e outras funcionalidades existentes;

- prover acesso aos conteúdos didáticos em qualquer lugar e a qualquer momento, de acordo com a conectividade do dispositivo;

- aumentar as possibilidades de acesso ao conteúdo, incrementando e incentivando a utilização dos serviços providos pela instituição, educacional ou empresarial;

- expandir o corpo de professores e as estratégias de aprendizado disponíveis, através de novas tecnologias que dão suporte tanto à aprendizagem formal como à informal;

- expandir os limites internos e externos da sala de aula ou da empresa, de forma ubíqua;

- fornecer meios para o desenvolvimento de métodos inovadores de ensino e de treinamento, utilizando os novos recursos de computação e de mobilidade.

Já Saccol e Reinhard (2005) comentam que o uso das TMSF pode trazer uma série de vantagens, mas cada vantagem analisada precisa considerar possíveis contrapontos, por exemplo: é possível aos usuários da tecnologia despender mais tempo em campo e menos tempo em tarefas de "bastidores" no escritório ou trabalhar em determinados "tempos mortos", muito embora as limitações técnicas e ergonômicas das TMSF e o próprio contexto do trabalho móvel possam por vezes impor restrições a isso; é possível localizar pessoas e ser localizado com maior rapidez e frequiência, assim como trocar dados de forma mais rápida e fácil, em diferentes locais e momentos, o que contribui para os processos de tomada de decisão - por outro lado uma sobrecarga, muitas vezes gerada pela fácil replicação de dados, aumenta consideravelmente.

A seguir é realizada uma descrição da metodologia empregada.

\section{Metodologia}

A natureza da pesquisa fundamentou-se numa abordagem exploratória e qualitativa. Optou-se por utilizar o método de "Estudo de Caso" por melhor se adequar ao contexto da pesquisa. $\mathrm{O}$ estudo de caso é uma estratégia de pesquisa que contribui para a pesquisa do objeto em relação a seu contexto. Assim, o estudo de caso serviu como recorte metodológico e a pesquisa participante serviu como modo de interlocução entre os sujeitos, especificamente no segundo caso. Streck e Brandão (2006, p. 52) colocam que "na pesquisa participante parto de um duplo reconhecimento de confiança em meu 'outro', naquele que procuro transformar de 'objeto de minha pesquisa' em 'cosujeito' de nossa investigação".

O primeiro estudo de caso se referiu ao processo formativo constituído por um Workshop chamado "Tecnologias Móveis e Sem Fio: o novo paradigma da ubiqüidade e suas possibilidades de aplicação", desenvolvido junto a uma equipe de colaboradores

V. $7 \mathrm{~N}^{\circ}$ 3, dezembro, 2009 
da GSI (Gerência de Sistemas de Informação) da UNISINOS. Ao todo participaram treze colaboradores da GSI.

O segundo estudo de caso correspondeu a uma oficina temática desenvolvida com uma equipe do SCH (Secretariado de Ciências Humanas) da UNISINOS. Este segundo Estudo de Caso teve caráter de pesquisa participante, conforme citado anteriormente e se refere ao desenvolvimento e análise de uma prática pedagógica com o uso das TMSF numa perspectiva dialogada, colaborativa e cooperativa. Ao todo participaram doze colaboradores da $\mathrm{SCH}$.

A pertinência da escolha dos casos está no fato das práticas pedagógicas se desenvolverem com distintos grupos de sujeitos que atuam de forma não fixa: os chamados trabalhadores móveis, cuja interação é tensionada pela introdução de um novo elemento, no caso ligado às TMSF.

Para a pesquisa empírica, foi utilizado um protótipo, o Ambiente Virtual de Aprendizagem com Mobilidade (AVAM) denominado COMTEXT, modelado e construído no contexto da pesquisa interdisciplinar "Aprendizagem com Mobilidade no contexto organizacional". Em ambas capacitações foram utilizados os seguintes materiais/instrumentos: observação, e-mail, interações realizadas pelos participantes no diário, chat, fórum, skype e questionários.
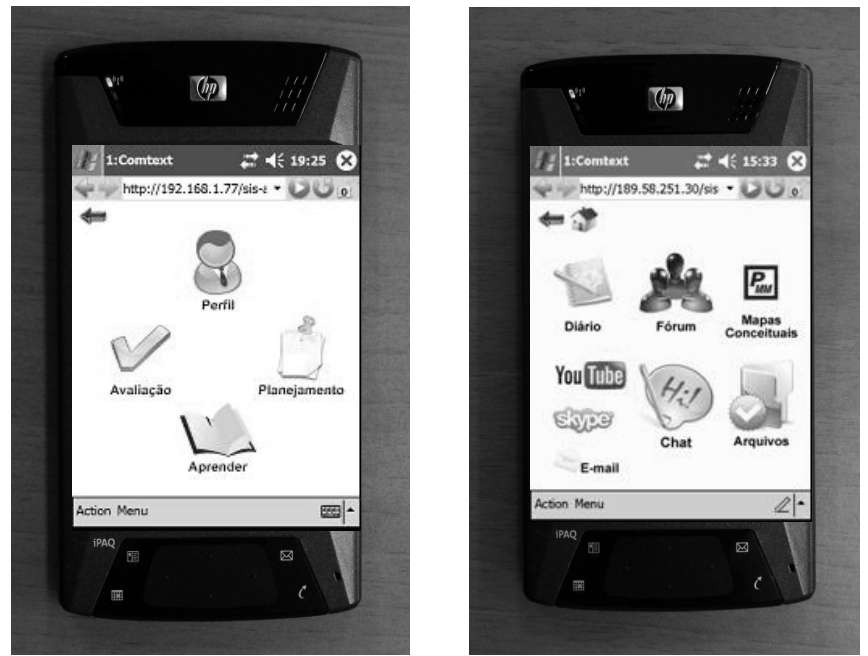

Figura 1 - Protótipo COMTEXT (Ambiente de Competência em Contexto) - Módulo Principal e Módulo Aprender, respectivamente.

Do ponto de vista da equipe do desenvolvimento do projeto, para que o $\mathrm{m}$ learning possa oferecer novas possibilidades de aprendizagem num contexto de mobilidade, é necessário, fundamentalmente, repensar os paradigmas educacionais, as concepções de aprendizagem, bem como as práticas pedagógicas desenvolvidas. Atualmente, um número significativo de sujeitos-trabalhadores passa por inúmeras experiências educacionais e verificam que muitas vezes elas são incipientes e não atendem as suas necessidades de aprendizagem. Acredita-se que um modelo que esteja fundamentado por uma concepção epistemológica interacionista-construtivistasistêmica possa dar conta de ajudar os sujeitos-trabalhadores a desenvolver competências necessárias para atuar num contexto de mobilidade.

Assim, o desenvolvimento do COMTEXT está fundamentado na concepção epistemológica interacionista-construtivista-sistêmica, na qual o sujeito num processo

\footnotetext{
${ }^{1}$ Ver mais detalhes sobre o projeto em: http://www.inf.unisinos.br/ mobilab/ Acesso em: 20/03/2009. V. $7 \mathrm{~N}^{\mathrm{o}}$ 3, dezembro, 2009
} 
de interação com o meio físico e social, constrói conhecimentos, entendendo que o processo de conhecimento é compreendido como sendo um todo integrado cujas propriedades fundamentais têm sua origem nas relações entre suas partes. Constituído de sub-sistemas que se inter-relacionam formando uma rede em que estes estão interligados e são interdependentes, de forma que o todo é maior que a soma das partes, pois envolve as partes e fundamentalmente as relações entre elas.

A seguir são descritas as características dos dois casos que fizeram parte da presente pesquisa.

\subsection{Características do Workshop e da Oficina Temática}

Ambas as capacitações foram desenvolvidas no contexto da Aprendizagem com mobilidade, por meio do uso de iPAQs HP 4700 Pocket PC e do ambiente COMTEXT.

O Workshop "Tecnologias Móveis e Sem Fio: o novo paradigma da ubiqüidade e suas possibilidades de aplicação" teve como objetivo promover a compreensão e discussão do novo paradigma da ubiqüidade e suas possíveis aplicações para a UNISINOS. A escolha se deu, em função de serem trabalhadores móveis, isto é, exercerem suas atividades profissionais em diferentes pontos físicos da UNISINOS e por utilizarem diariamente a tecnologia, uma vez que atuam gerenciando todo o Sistema de Informação da Universidade. Dessa forma, além de adquirirem conhecimentos sobre a temática do Workshop, puderam contribuir no teste do protótipo COMTEXT, auxiliando assim em melhorias e ajustes para práticas posteriores.

O Workshop teve a duração de duas semanas, num total de 15 horas, sendo dois encontros presenciais físicos de 1 hora e 30 minutos de duração (um encontro de abertura e outro de encerramento) e os demais, totalizando 12 horas, realizado de forma presencial digital virtual (online). Nos encontros presencias digitais virtuais, que ocorreram num total de oito dias, as atividades foram guiadas por perguntas-eixo (tópicos de estudo/discussão), um tópico trabalhado por dia.

Como atividade prática final, o qual faria parte da avaliação do Workshop, foi proposta a elaboração de um projeto (hipotético) em grupos considerando possibilidades de aplicação dessas tecnologias móveis e sem fio para as atividades da UNISINOS. A partir do primeiro caso (Workshop), algumas questões serviram de elementos para subsidiar o desenvolvimento da Oficina Temática.

A Oficina temática intitulada "Diálogo, Colaboração e Cooperação no contexto do trabalho coletivo" teve como objetivo promover a compreensão dos conceitos de Diálogo, Colaboração e Cooperação e sua importância para o desenvolvimento de atividades que exigem articulação em equipe, por meio de vivências de práticas pedagógicas colaborativas no contexto da Aprendizagem com Mobilidade.

As atividades foram desenvolvidas na modalidade b-learning, num total de 30 horas, quando tínhamos alguns encontros presenciais físicos (1h30min de duração dois por semana) e os demais presenciais digitais virtuais (o restante das horas trabalhadas), utilizando o Ambiente COMTEXT.

Durante a prática pedagógica, foi proposta a elaboração de um projeto de aprendizagem (FAGUNDES et al., 1999) cujo tema emergisse de um consenso conforme necessidades individuais e de grupo e, que fizesse parte de seus contextos profissionais, culminando numa posterior aplicação prática no dia-a-dia. Para desenvolver o projeto de aprendizagem deveriam encontrar parceiros (entre os colegas), conforme interesses e curiosidades compartilhados sobre o problema a ser resolvido. Assim, os participantes fizeram primeiramente um levantamento de suas dúvidas temporárias e suas certezas provisórias em relação ao problema que gerou o projeto.

V. $7 \mathrm{~N}^{\circ}$ 3, dezembro, 2009 


\section{Considerações Finais}

Neste estudo buscou-se observar as potencialidades motivadas pela interação dos sujeitos com essa tecnologia. A partir da análise dos dados e dos achados, seguem algumas reflexões e possibilidades implícitas no uso das TMSF:

- Favorecer a criação de ambientes que possibilitem ao sujeito aprendiz continuar a aprender, mesmo estando fora da instituição/lugar formal de ensino e/ou seja, em contexto de mobilidade;

- Ter um planejamento aberto, flexível, isto é, uma dinâmica que se adapte e respeite fundamentalmente o contexto dos sujeitos envolvidos nesse processo;

- Possibilitar espaços de reflexão, por meio do saber construído (as aprendizagens) do sujeito, no plano individual, e por meio da interação e do diálogo com os colegas e o professor-orientador, no plano coletivo, além da reflexão desses sujeitos da influencia dessas TMSF nas suas práticas diárias, para desse modo, revisarem e reconfigurarem suas práticas;

- Propiciar atividades dando um valor especial às sensações, subjetividades, impressões, desejos e afetos dos sujeitos, imbricados no processo educativo, não esquecendo os objetivos de seu uso, sobretudo no contexto da mobilidade, devido às restrições técnicas e ergonômicas dos dispositivos móveis, não se esquecendo de prevalecer as questões didático pedagógicas em relação às questões tecnológicas;

- Pensar numa forma de adaptar seu melhor seu uso ao contexto dos sujeitos, para não acabar limitando a participação por parte dos sujeitos e a própria "hospedagem" dessas tecnologias;

- Propiciar encontros (sejam presenciais físico ou online) como espaços de apoio e de "encontro", principalmente para resolução de dúvidas, trocas e questionamentos;

- Pensar na mediação pedagógica, numa perspectiva dialógica entre alunos e aluno-professor, na qual o professor tem a função de orientador, problematizador, não limitando o papel do professor a somente fornecer informações, mas assumindo a mediação das interações entre aluno-informação-dispositivo-aluno;

- Pensar no uso de projetos de aprendizagem como possibilitador da configuração de prática pedagógica que instiga a ação, a interação dos sujeitos, mediada pelo professor-orientador, contribuindo para a formação de sujeitos autônomos, reflexivos, e com alto nível de autoria e ainda propiciar processos de cooperação;

- Perceber como alguns desafios tecnológicos e ergonômicos, de tempo e de espaço, podem afetar ou restringir o seu uso nas práticas pedagógicas no contexto da mobilidade;

- Não esquecer do fator "espaço físico (contexto)" que pode de certa forma "limitar" a mobilidade, o uso efetivo dela, devido principalmente às restrições tecnológicas de acesso a rede em diversos pontos;

- Possibilitar o uso "efetivo" da mobilidade, que além de poder expandir os limites das práticas podem ainda propiciar outras possibilidades, como por exemplo, localização e formação de grupos conforme afinidades dos sujeitos, anotações de observações em saídas a campo, entre outras.

Esta pesquisa consistiu-se em um espaço de experiência e convite à reflexão sobre o uso das TMSF na educação sem apresentar medidas pontuais e passageiras, soluções imediatas de trabalho que apontam a máquina como centro do processo de aprendizagem. A proposta foi centrada na interação sujeitos-tecnologia-sujeitos, que viabiliza o processo de produção de conhecimentos democraticamente nas diferentes áreas do conhecimento. 


\section{Referências}

CIBORRA, C. The labyrinths of information: challenging the wisdom of systems. New York: Oxford Press, 2002.

CASTELLS, Manuel. A sociedade em rede. 8. ed. São Paulo: Paz e Terra, 2005.

FAGUNDES, Léa da Cruz; SATO, Luciane Sayuri; MAÇADA, Débora Laurino. Projeto? O que é? Como se faz? In: __ . "Aprendizes do Futuro: as inovações começaram!" Coleção Informática para a mudança na Educação. Brasília, MEC. http://mathematikos.psico.ufrgs.br/textos.html, 1999.

FERNANDES, Cleoni Maria Barbosa. In: MOROSINI, Marília Costa; ROSSATO, Ricardo (Ed.) et al. Enciclopédia de pedagogia universitária: glossário. Brasília: INEP, 2006.

LEMOS, André. Cibercultura, tecnologia e vida social na cultura contemporânea. Porto Alegre: Sulina, 2002.

MARÇAL, Edgar; SANTOS, Raniery; VIDAL, Creto, ANDRADE, Rossana; RIOS, Riverson. MuseuM: Uma Aplicação de m-learning com Realidade Virtual. Seminário Integrado de Software e Hardware. São Leopoldo: Unisinos. http://www.lia.ufc.br/ great/artigos/museuM.pdf, 2005.

MEIRELLES, Luiz Fernando Tavares; TAROUCO, Liane Margarida Rockenbach; ALVES, Carlos Vinicius Rasch. Telemática Aplicada à Aprendizagem com Mobilidade. In: RENOTE - Revista Novas Tecnologias na Educação, Porto Alegre. V. $2 \mathrm{~N}^{\mathrm{o}}$ 2, novembro, 2004.

REINHARD, Nicolau; SACCOL, Amarolinda Zanela; SCHLEMMER, Eliane; BARBOSA, Jorge; KRISTOFFERSEN, Steinar. Aprendizagem com mobilidade no contexto organizacional, 2007. Disponível em: http://www.inf.unisinos.br/ mobilab/.

A. Saccol; N. Reinhard. (2005) Processo de Adoção e Decorrências da Utilização de Tecnologias de Informação Móveis e Sem Fio no Contexto Organizacional. In: XXIX EnANPAD, 2005, Brasília, v. 1, p. 1-16, 2005.

SCHLEMMER, E. A aprendizagem com o uso das Tecnologias Digitais: Viver e Conviver na Virtualidade. Série-Estudos (UCDB), Campo Grande, v. 1, n. 19, p. 103 126, 2005.

SILVERMAN, Barry G. Computer Supported Collaborative Learning (CSCL). Computers Education, 1995.

STRECK, Danilo R. e BRANDÃO, Carlos Rodrigues. A pesquisa participante e a partilha do saber: uma introdução. In: STRECK, Danilo R. e BRANDÃO, Carlos Rodrigues (orgs.). Pesquisa Participante: a partilha do saber. Aparecida, SP: Idéias e Letras, 2006. 